\title{
Occurrence and detrimental effects of the bivalve-inhabiting hydroid Eutima japonica on juveniles of the Japanese scallop Mizuhopecten yessoensis in Funka Bay, Japan: relationship to juvenile massive mortality in 2003
}

\author{
Katsuhisa Baba • Akira Miyazono • Keiji Matsuyama • \\ Shoui Kohno • Shin Kubota
}

Received: 20 July 2006 / Accepted: 31 January 2007 / Published online: 20 February 2007

(C) Springer-Verlag 2007

\begin{abstract}
In November 2003, we first observed prevalent occurrence of a hydroid, Eutima japonica, on soft body tissues of age zero Japanese scallop (Mizuhopecten yessoensis) juveniles cultured in large areas of Funka Bay, Hokkaido. The occurrence coincided with massive death of juvenile scallops. A major objective was to clarify ecological relationships between the symbionts, and to infer the relationship between symbiosis and the massive mortality. To do this, we investigated distributions of association rates of hydroids with juvenile scallops at 15-34 sites over 3 years (2003-2005), with age one adult scallops at 24 sites in 2003, and with mussels at 13 sites in 2004 . We studied seasonal changes in association rates with juvenile scallops, and numbers of polyps per juvenile scallop at three sites from November 2003 to June 2004. We also quantified the hydroid impacts on juvenile scallop shell length growth
\end{abstract}

Communicated by S. Nishida.

K. Baba $(\square) \cdot$ A. Miyazono

Hokkaido Hakodate Fisheries Experiment Station,

1-2-66 Yunokawa, Hakodate, Hokkaido 042-0932, Japan

e-mail: babak@fishexp.pref.hokkaido.jp

K. Matsuyama

Hokkaido Tokai University,

5-1-1-1 Minamisawa, Sapporo, Hokkaido 005-8601, Japan

S. Kohno

Hokkaido Mariculture Fisheries Experiment Station,

1-156-3 Funami, Muroran, Hokkaido, 051-0013, Japan

S. Kubota

Seto Marine Biological Laboratory,

Field Science Education and Research Center,

Kyoto University, Shirahama,

Wakayama, 649-2111, Japan and triglyceride accumulation in the digestive gland. The association rate of E. japonica polyps with juvenile scallops was high in large areas of Funka Bay in 2003, and overlapped the distribution of mussels bearing polyps. Association rates with age one adult scallops were very low in November 2003, even at the sites where polyps were very common on juvenile scallops. Levels of hydroid occurrence in juvenile scallops varies by year. We found that hydroids presence in juvenile scallops declined drastically in 2004 and 2005. The association rates with juvenile scallops, and numbers of polyps per juvenile scallop declined during winter, until they disappeared completely in the following June. Since polyps were rare in adult scallops, we believe that infection of juvenile scallops was probably initiated from the planulae produced by medusae released from polyps growing on Mytilus spp., especially M. galloprovincialis. Subsequently, the inhabitation spread intraspecifically and interspecifically. In juvenile scallops, inhabitation of polyps reduced shell length growth by $43 \%$, and triglyceride accumulation in digestive glands by $24-47 \%$. Inhabitation of E. japonica on juvenile scallop is best regarded as parasitism, rather than inquilinism or commensalism. Occurrence of polyps was probably not a direct lethal factor for juvenile scallops, because there were some sites where association rates were high, but mortalities were low. Massive mortalities in 2003 may have resulted from simultaneous impacts of heavy polyp load and stresses caused by the way in which the animals were handled (transferred from cages for preintermediate culture to cages for intermediate culture), because the massive mortality occurred within a month of the transfer. The presence of polyps in juvenile scallops does not affect the quality of the product in Funka Bay, because market size scallops are hydroid-free. 


\section{Introduction}

There are two genera of bivalve-inhabiting hydroids, Eutima and Eugymnanthea; both are classified in Hydrozoa, Leptomedusae, Eirenidae (Kubota 1992a). Polyps of these hydroids, which inhabit soft body parts of host bivalves, reproduce asexually by budding daughter polyps (Kubota 1983; Piraino et al. 1994). The polyp of Eutima releases a medusa with immature gonads, but with a well-developed feeding apparatus comprising long tentacles and a well-differentiated manubrium (Kubota 1983). In contrast, the polyp of Eugymnanthea releases a reproductively mature medusoid with an atrophic feeding apparatus that has no tentacles and a considerably reduced manubrium (Kubota 1979). The inhabitation spreads intraspecifically and interspecifically via swimming planula larva. Kubota (1991) proposed emending Japanese Eugymnanthea inquilina japonica Kubota 1979, formerly considered to be a subspecies of the Mediterranean Eugymnanthea inquilina, to Eugymnanthea japonica Kubota 1979, treating the two taxa as separate species mainly because of the differences between the medusoid stages. In Japan, Eutima japonica and Eugymnanthea japonica are distributed parapatrically, and only Eutima japonica occurs in Hokkaido, northern Japan (Kubota 1992a, b, 1997). These hydroids do not have strict host specificity, but they have host preferences (Kubota1992a, 1997). The common host of these hydroids is the mussel Mytilus galloprovincialis. Excepting $M$. galloprovincialis, the predominant host is Mytilus grayanus for Eutima japonica and Crassostrea gigas for Eugymnanthea japonica. There are no reports of the occurrence of bivalve-inhabiting hydroids in Japanese scallop [Mizuhopecten yessoensis (syn. Patinopecten yessoensis)].

The ecological relationships between Japanese Eutima japonica and Mediterranean Eugymnanthea inquilina and the host, the mussel Mytilus galloprovincialis, were studied quantitatively in the Sea of Japan and in the Mediterranean Sea by Kubota (1983) and Piraino et al. (1994), respectively. Eutima japonica and Eugymnanthea inquilina inhabit mussels longer than $15 \mathrm{~mm}$ and $40 \mathrm{~mm}$, respectively. The association rate of Eutima japonica with mussels is constant throughout the year, whereas the association rate of Eugymnanthea inquilina with mussels decreases at the onset of medusoid liberation in summer. Sexual reproduction occurs between June and November, and between June and August in Eutima japonica and Eugymnanthea inquilina, respectively. Both authors reported that inhabitation by hydroid polyps has no harmful effects on M. galloprovincialis. Indeed, Piraino et al. (1994) suggested that the relationship between the mussel and Eugymnanthea inquilina may be one of mutualism, rather than simple commensalism, because the polyps selectively ingest the sporocysts of trematodes, which parasitized mussels in the study area.

The annual aquaculture production of the Japanese scallop, M. yessoensis, in Funka Bay ranged from 92,000 to 141,000 t between 1999 and 2004 (Ministry of Agriculture, Forestry and Fisheries 2000-2005). Procedures for scallop culture in Funka Bay were described in Ito (1991). The spawning season of scallops is May. Seeds of the scallop are collected from June to July under natural conditions using spat collectors. The seeds are first raised in small-mesh net cages for 1 month (pre-intermediate culture), and subsequently in large-mesh net cages for 8 months (intermediate culture), and finally on hanging ropes for 1 year (main culture). Large part of the scallops are harvested between March and April, after about 1 year and 9 months from seed collection; and survivors constitute the spawning population, i.e., the scallops are sexually mature when they are 1 year old. In the summer 2003, extraordinary massive mortalities occurred among juvenile scallops cultured in Funka Bay. During a search for responsible factors, we found extensive populations of the bivalveinhabiting hydroid, Eutima japonica in juvenile scallops. The aims of this study are to clarify ecological relationship between a bivalve-inhabiting hydroid and its hosts, to quantify the impact of the polyps on juvenile scallops, and to infer the relationship between the inhabitation and the massive mortalities.

\section{Materials and methods}

\section{Distribution of Eutima japonica in Funka Bay}

To investigate the distribution of the Eutima japonica in Mizuhopecten yessoensis, Mytilus galloprovincialis, $M$. trossulus, and M. coruscus, we sampled the bivalves in Funka Bay (Table 1; Fig. 1). Excluding age one adult scallops, we collected about 30 individuals at each sampling site. Juvenile scallops were cultured as intermediate culture in a set of net cages (total length $1.8 \mathrm{~m}$ ) made of 12 component cages. We sampled age zero juvenile scallops (mean shell length: $36.3 \mathrm{~mm}$, $\mathrm{SD}=5.5$ ) from one or two component cages positioned at the upper of the set of net cages for three years (2003-2005). We investigated adult scallop once in November 2003 because polyp occurrences in adult scallop were rare, even at the sites where association rates of hydroids with juvenile scallops were very high in 2003. We photographed (under dissecting 
Table 1 Summary of samples indicating distribution of the hydroid Eutima japonica inhabitation in bivalves (Mizuhopecten yessoensis, Mytilus spp.) in Funka Bay, Hokkaido, Japan

\begin{tabular}{|c|c|c|c|c|c|c|c|c|}
\hline \multirow[t]{2}{*}{ Figures } & \multicolumn{2}{|l|}{ Sample (host) } & \multirow[t]{2}{*}{ Year } & \multirow[t]{2}{*}{ Month } & \multicolumn{3}{|c|}{ Sampling sites } & \multirow{2}{*}{$\begin{array}{l}n \\
\text { Mean }\end{array}$} \\
\hline & Species & Age & & & a & $N$ & Site numbers & \\
\hline $3 a, f$ & M. yessoensis & 0 & 2003 & November & $\mathrm{CF}$ & 34 & $2-35$ & 33.3 \\
\hline $3 b$ & M. yessoensis & 0 & 2004 & October or December & $\mathrm{CF}$ & 15 & $2,4,11,13,15,17,18,20-24,27,30,33$ & 28.5 \\
\hline $3 c$ & M. yessoensis & 0 & 2005 & November & $\mathrm{CF}$ & 15 & $4,7,11,13,15,17,18,20-25,27,30$ & 29.9 \\
\hline $3 \mathrm{~d}$ & M. yessoensis & 1 & 2003 & November & $\mathrm{CF}$ & $\begin{array}{l}18 \\
6^{\mathrm{b}}\end{array}$ & $\begin{array}{l}14,17-21,23-34 \\
4,6,11,13,15,22\end{array}$ & $\begin{array}{r}11.1 \\
141.2\end{array}$ \\
\hline $3 e$ & Mytilus spp. & c & 2004 & March & FH & 13 & $1-4,11,13,14,18,23,27,31,33,35$ & 29.4 \\
\hline
\end{tabular}

Corresponding figures are indicated in column 1

$N$ number of sampling sites, $n$ number of individual bivalves collected

${ }^{a} C F$ culture facilities, $F H$ fishermen's harbors

${ }^{\mathrm{b}}$ Intensive investigation sites

${ }^{c}$ Unknown

Fig. 1 Location of Funka Bay, sampling sites and number of sites

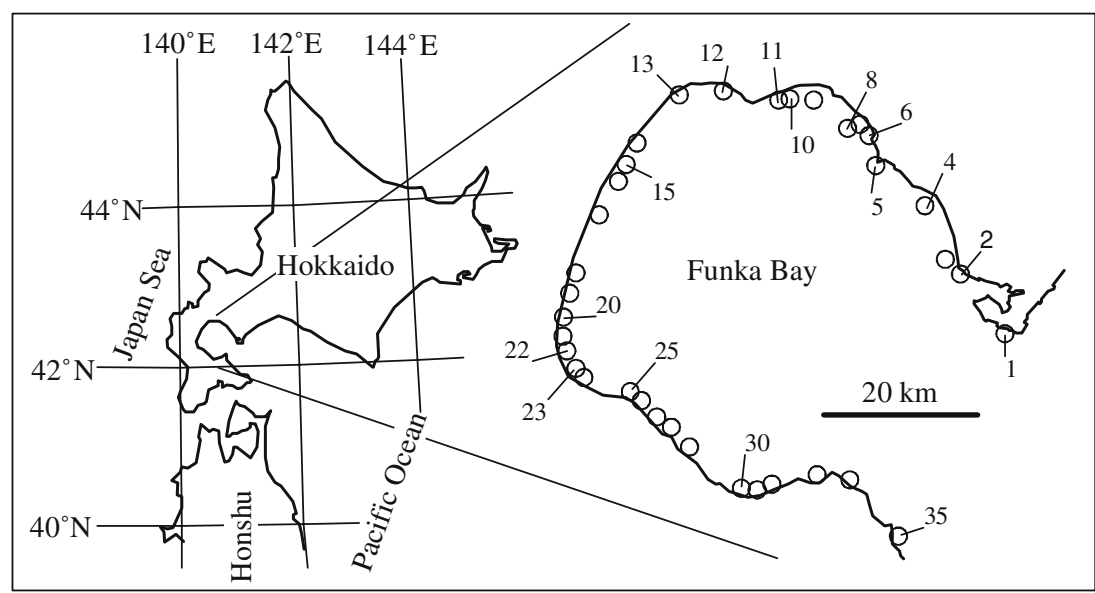

microscope) live polyps and medusae just after budding off, and juvenile scallops heavily inhabited by polyps. Adult scallops were cultured by the ear-hanging method on a $13 \mathrm{~m}$ rope. To sample age one adult scallops, we chose sites $4,6,11,13,15$, and 22 for intensive investigation and from these sites we collected large numbers of adult scallops (mean shell length: $113.0 \mathrm{~mm}, \mathrm{SD}=9.9$ ) from 50 to 226 individuals (average 141.2). At the other 18 sites, we collected eight to 19 adult scallops (average 11.1, mean shell length: $96.5 \mathrm{~mm}, \mathrm{SD}=7.6$ ) from the upper parts of the culture ropes. We collected about 30 wild specimens of mussels with shell lengths $>20 \mathrm{~mm}$ at Fishermen's Harbors in March 2003. To seek out a possible source population for polyps that infect scallops, we investigated mussels with shell length $>20 \mathrm{~mm}$ (the size which hydroids inhabit Kubota 1983). Our hypothesis was that planulae formed by medusae released from polyps inhabiting in the mussels were the source of the scallop hydroid population. The association rate of hydroids with Mytilus galloprovincialis is constant through a year in Oshoro Bay, Hokkaido (Kubota 1983); it was therefore considered appropriate to make a single survey of the distribution of hydroids in Mytilus spp.

Juvenile scallops were fixed in 5\% formalin-seawater. After fixation, the juveniles were observed under a dissecting microscope and checked for the presence of hydroids. Polyps were counted after removal from each juvenile scallop. We also counted the medusa buds formed by polyps growing on the juvenile scallops collected from ten sites (sites 2-12). To investigate mortality of juvenile scallop, we counted number of live and dead juveniles except for sites 10 and 12 where producers removed dead shells before our investigations. Except for sites 10 and 12, dead shells were not removed from any of our study locations. A single death was indicated by pair of conjoined valves, or by two separated dead valves. For adult scallops and mussels, we observed the samples under a dissecting microscope without fixation soon after sampling (within a day for the scallops, and within a few days for the mussels). After sampling mussels for hydroids, assignments 
to Mytilus species were carried out according to Okutani et al. (2000). Differentiation between M. galloprovincialis and $M$. trossulus was based on characteristics of the subligamental nacre, according to Kuwahara (2001).

\section{Seasonality of polyp inhabitation in juvenile scallops}

To quantify seasonal changes in association rate, the numbers of polyps per juvenile, and mortality, we sampled the juveniles monthly from two to six cages of intermediate culture positioned at the top of a set of net cages at three sites (sites 11,15 and 23). Collections were made until occurrence of polyp become negligible, from November 2003 to March 2004 at sites 11 and 15, and from November 2003 to June 2004 at site 23. We were able to investigate mortalities at each of the sites before the aquaculture producers cleared out dead juveniles (until March 2004 at site 11, until February 2004 at site 15, and until April 2004 at site 23).

The juveniles were fixed in $5 \%$ formalin-seawater. After fixation, shell lengths of live individuals and right shells of dead individuals were measured to $0.02 \mathrm{~mm}$ precision with a digital caliper (Digimatic caliper, Mitsutoyo Ltd, Kawasaki), and live and dead shells were counted. A single death was indicated by pair of conjoined valves, or by two separated dead valves. Polyps were removed and counted. We counted the numbers of polyps with medusa buds in samples collected in November and December at sites 15 and 23.

We analyzed shell length compositions at site 15 to estimate the time of death for the juveniles, and to compare shell length compositions between dead shell, hydroid-free and hydroid-bearing individuals. High mortalities and high association rates at site 15 made this an appropriate location for this comparison. To estimate precisely when massive death occurred, shell length data for live and dead juveniles sampled at site 15 (from same producer) on 15 October 2003 were provided by the Hokkaido Oshima Hokubu District Fisheries Training Center (228-1 Morikawa, Mori, Hokkaido 049-2313, Japan), which has been investigating mortality and shell lengths of juvenile scallops each October since 1996.

To evaluate the influence of E. japonica inhabitation on shell length growth, we analyzed data taken from site 23 where low mortalities and high association rates were observed because we needed to compare large number of shell length data from hydroid-bearing and hydroid-free juveniles. Shell lengths were standardized to eliminate the effects of variation in shell length on growth. The standardization was attained by ${ }_{\text {std }} \mathrm{SL}_{i}=\left(\mathrm{SL}_{i}-\mathrm{SL}_{m}\right) \mathrm{SL}_{\mathrm{sd}}^{-1}$, where ${ }_{\text {std }} \mathrm{SL}_{i}$ is the standard- ized shell length of the $i$ th individual, $\mathrm{SL}_{i}$ is the shell length of the $i$ th individual, $\mathrm{SL}_{m}$ is the mean and $\mathrm{SL}_{\mathrm{sd}}$ is the standard deviation of the shell lengths. The shell lengths and the standardized shell lengths were compared between the hydroid-bearing and hydroid-free juveniles. Shell length variation, which is generally expressed as the standard deviation, usually increases with growth. As shell length variation increases, length differences also increase between simple categories of individuals, such as the larger one third and the smaller two thirds; this does not occur when shell length is standardized. Increasing difference in standardized shell length is not attributable to shell length variation with growth. Influences of mortality on this analysis might be negligible because mortalities were low in site 23 during our investigation.

\section{Triglyceride in the digestive gland}

To evaluate the influence of $E$. japonica inhabitation on nutritional status of juvenile scallops, we compared concentrations of triglyceride (a nutrient stored in digestive gland in scallops Barber and Blake 1991) in individuals that bore polyps and those that did not. Twenty juveniles were sampled from three cages positioned at top, middle and bottom of a set of net cages at site 20 on 15 November 2004.

In chosen individuals, half of the digestive gland on the side distant from the mouth was excised with scissors and weighted by laboratory weighting (AE-106, Mettler Toledo, USA) (mean mass removed: $0.17 \mathrm{~g}$, $\mathrm{SD}=0.048$ ), and the rest of the soft body was fixed with $5 \%$ formalin-seawater to check hydroid occurrence and location. The polyps were counted after removal. The excised digestive glands were stored at $-40^{\circ} \mathrm{C}$ overnight. On the next day of the sampling, the excised digestive gland was homogenized in $5 \mathrm{ml}$ of ethanol-diethyl ether (1:1) with a stainless steel homogenizer (Physcotronm, Nition, Chiba, Japan). The homogenates were centrifuged at $2,500 \mathrm{~g}$ for $20 \mathrm{~min}$ at $5^{\circ} \mathrm{C}$. The content of triglyceride in the supernatants was measured with a triglyceride test kit (triglyceride E-test, WAKO, Osaka, Japan). Ten $\mu$ l of the supernatant were mixed with $250 \mu \mathrm{l}$ of the detection solution from the kit on a 96 well microplate (Nunc, Roskilde, Denmark), and the mixture was incubated at $37^{\circ} \mathrm{C}$ for $5 \mathrm{~min}$. After incubation, absorbance at $570 \mathrm{~nm}$ was measured with a microplate reader (Model 680, Bio-Rad). The contents of triglyceride were calculated with a serially diluted standard solution of glycerin, and the concentrations $\left(\mathrm{mg} \mathrm{g}^{-1}\right)$ were calculated based on the wet weight of the digestive gland for each individual. 


\section{Results}

Distribution of Eutima japonica and mortality of juvenile scallop in Funka Bay

Well-developed polyps of Eutima japonica had medusa buds (Fig. 2a). The perradial tentacular bulb of medusae had black pigment (Fig. 2b). This is characteristic of the genus Eutima, but not Eugymnanthea (Kubota 1991, 1992b). In heavily inhabited juvenile scallops, polyps completely covered the foot and periphery of the mouth (Fig. 2c). The polyps appeared to act as an impediment to the feeding mechanisms of juvenile scallops.

The association rate of Eutima japonica polyps with juvenile scallop was high in large areas of Funka Bay in
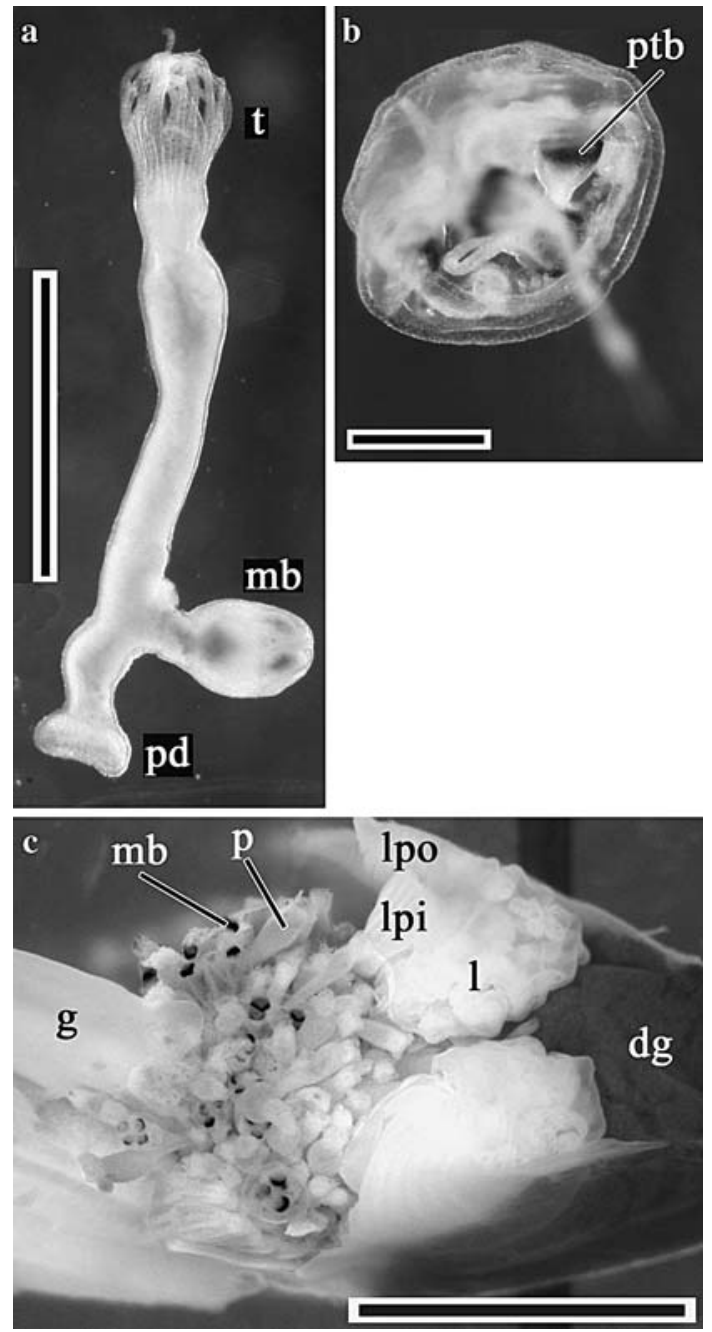

Fig. 2 Eutima japonica a polyp, b medusa just after budding off, c polyps inhabiting a juvenile Japanese scallop Mizuhopecten yessoensis. $m b$ medusa bud, $p$ polyp, $p d$ pedal disc, $p t b$ perradial tentacular bulb, $t$ tentacle (of E. japonica). $d g$ digestive gland, $g$ gonad, $l$ lip, lpi inner labial palp, lpo outer labial palp (of Mizuhopecten yessoensis). Bars are $1 \mathrm{~mm}$ in $\mathbf{a}, 0.2 \mathrm{~mm}$ in $\mathbf{b}$, and $5 \mathrm{~mm}$ in $\mathbf{c}$
2003, overlapping the distribution of the mussels bearing polyps (in Fishermen's Harbors) (Fig. 3a, e). Among the areas investigated, there were four categories of relationship between the polyp/scallop association rates and mortalities of juvenile scallops: I, low association rate and high mortality (site 9-11); II, high association rate and high mortality (site 13-18); III, high association rate and low mortality (site 19-27); IV, low association rate and low mortality (site $2-8$ and 28 35) (Fig. 3a, f). The association rates were very much lower in 2004 and 2005 than in 2003 (Fig. 3a-c). For both 2004 and 2005, the highest occurrence of polyps in juvenile scallops was in sites 18-24. Polyp occurrence in adult scallops was rare, even at the sites where association rates with juveniles were very high in 2003 (Fig. 3a, d).

In November 2003, inhabitation in juvenile scallops was observed at 27 of 34 sites. The association rates with juvenile ranged from 0.0 to 100 . An average of $358.1(\mathrm{SD}=198.7)$ polyps occurred on each juvenile. An average $14.3 \%(\mathrm{SD}=7.5)$ of the polyps at sites 2-12 had a medusa bud.

There were high association rates of polyps with Mytilus spp. individuals in Fishermen's Harbors in all area in Funka Bay except site 2 (Fig. 3e). But the inhabitation was not observed outside the bay at sites 1 and 35 (Fig. 3e). Of 382 mussel samples, 379 (99.2\%) were $M$. galloprovincialis, two $(0.5 \%)$ were $M$. coruscus, and one $(0.3 \%)$ was M. trossulus. E. japonica occurred in M. galloprovincialis and M. trossulus. The single $M$. trossulus specimen (bearing polyps) was found at site 29. The two M. coruscus (polyp-free) were collected at site 11 where E. japonica inhabited $13 \mathrm{M}$. galloprovincialis individuals out of 28 (46.4\%).

\section{Seasonality of inhabitation in juvenile scallops}

Association rates of polyps with juvenile scallops, and numbers of polyps per juvenile scallop declined after November 2003, and polyps disappeared completely in the following June (Table 2; Fig. 4a-c). The seasonality of decline and disappearance of the polyps varied by site. There were no seasonal changes in mortality rates that could account for the seasonal changes in the association rates and the number of polyps per juvenile scallop. The hydroid disappeared first from site 11, then from site 15 , and lastly from site 23 . The percentages of the polyps with medusa buds were $28.9 \%$ $(n=391)$ and $23.5 \%(n=468)$ in November, and $1.1 \%$ $(n=267)$ and $0.7 \%(n=407)$ in December at sites 15 and 23 , respectively.

Although shell lengths of both hydroid-bearing and hydroid-free live juvenile scallops became gradually 
Fig. 3 Eutima japonica and Mizuhopecten yessoensis, distributions a-c, association rate of E. japonica with age zero M. yessoensis from 2003 to 2005; $\mathbf{d}$ association rate of E. japonica with age one M. yessoensis in 2003; e association rate of E. japonica with Mytilus spp. in 2004; $\mathbf{f}$ mortality of age zero M. yessoensis in 2003

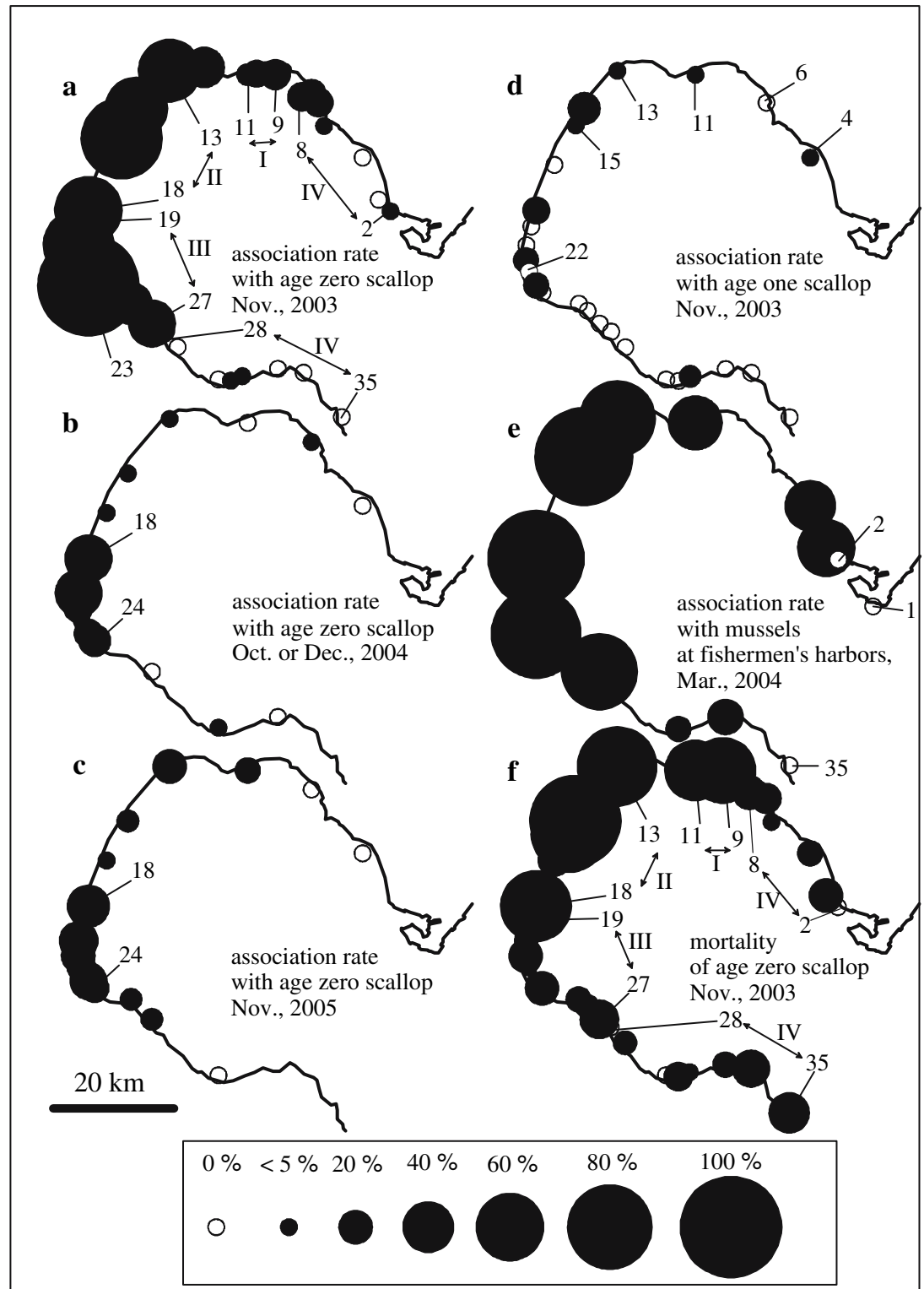

larger from October 2003 to February 2004 at site 15, shell lengths of dead juveniles changed little over this time period (Fig. 5). We observed similar results at sites 11 and 23. In site 15, modal shell lengths of dead juveniles were between 15 and $20 \mathrm{~mm}$ and between 20 and $25 \mathrm{~mm}$, and most shells were less than $30 \mathrm{~mm}$. On 14 September 2003, the aquaculture producer transferred the juveniles from pre-intermediate culture cages to intermediate culture cages (this transfer is a common procedure in Funka Bay scallop culture). Therefore, massive deaths in this sample probably occurred between 14 September and 15 October 2003. After the massive die off, mortalities were likely more limited. Aquaculture producers who provided scallop samples in 2003, carried out the transfer between late August and early October (mainly mid or late September).
Although shell lengths were significantly different between hydroid-bearing and hydroid-free live juvenile scallops in January and February $(P \leq 0.05$, Kruskal-Wallis test), they were not significantly different in November and December, in the early phase of symbiosis (Fig. 5a-e).

Effects of Eutima japonica inhabitation on juvenile scallops

Shell lengths were significantly different between polyp-bearing and polyp-free juvenile scallops at site 23 (Fig. 6a). There were also differences when using standardized shell length, especially from December to February when juveniles were inhabited by large number of polyps (Figs. 4c, 6b). The differences increased 
Table 2 Mizuhopecten yessoensis, seasonal changes in association rates of Eutima japonica with juvenile scallops, number of polyps per juvenile scallop, and mortalities of juvenile scallops at three sites in Funka Bay, Hokkaido, Japan

\begin{tabular}{|c|c|c|c|c|c|c|c|c|c|c|}
\hline \multirow[t]{2}{*}{ Figures } & \multirow[t]{2}{*}{ Site } & & \multicolumn{8}{|c|}{ Sampling season (year, month) } \\
\hline & & & 2003 November & December & 2004 January & February & March & April & May & June \\
\hline \multirow[t]{4}{*}{$4 \mathrm{a}$} & \multirow[t]{4}{*}{11} & $n$ & 71 & 72 & 64 & 59 & 59 & & & \\
\hline & & Mortality (\%) & 67.6 & 70.8 & 73.4 & 74.6 & 61.0 & & & \\
\hline & & Association (\%) & 4.3 & 14.3 & 0 & 26.7 & 0 & & & \\
\hline & & Polyp (n/individual) (SEM) & 905.0 & $622.0(281.0)$ & 0.0 & $32.7(9.3)$ & 0.0 & & & \\
\hline \multirow[t]{4}{*}{$4 b$} & \multirow[t]{4}{*}{15} & $n$ & 273 & 133 & 137 & 90 & 45 & & & \\
\hline & & Mortality (\%) & 88.3 & 42.9 & 62.9 & 55.4 & - & & & \\
\hline & & Association (\%) & 53.1 & 60.5 & 56.9 & 20.0 & 2.2 & & & \\
\hline & & Polyp (n/individual) (SEM) & $184.3(42.5)$ & $201.1(34.1)$ & $49.8(10.2)$ & $7.3(6.0)$ & 3.0 & & & \\
\hline \multirow[t]{4}{*}{$4 c$} & \multirow[t]{4}{*}{23} & $n$ & 20 & 53 & 52 & 52 & 66 & 66 & 30 & 30 \\
\hline & & Mortality (\%) & 0.0 & 3.8 & 5.8 & 3.9 & 10.6 & 3.0 & - & - \\
\hline & & Association (\%) & 100.0 & 74.5 & 69.4 & 68.0 & 62.7 & 14.1 & 3.3 & 0.0 \\
\hline & & Polyp (n/individual) (SEM) & $473.0(130.2)$ & $337.1(27.8)$ & $537.3(66.0)$ & $198.3(25.0)$ & $122.7(18.7)$ & $3.4(0.8)$ & 2.0 & 0.0 \\
\hline
\end{tabular}

Corresponding figures are indicated in column 1

- Mortality was not investigated because dead individuals were removed before investigation

with shell size in both shell lengths and standardized shell lengths. Use of standardized shell length clearly suggests that there are effects attributable to polyp inhabitation alone. From December to March, juvenile scallops free of polyps grew from 47.1 to $59.8 \mathrm{~mm}$ $(12.7 \mathrm{~mm})$ average shell length, while inhabited scallops grew on average from 43.2 to $50.4 \mathrm{~mm}(7.2 \mathrm{~mm})$; thus shell length growth was inhibited by $43.3 \%$. Data on shell length differences between polyp-bearing and polyp-free juvenile scallops were not available for November at site 23 (because the association rate was $100 \%)$. The difference in shell lengths was minimal at the early phase of symbiosis in December.

Triglyceride concentrations in the digestive glands were significantly different between polyp-bearing and polyp-free juvenile scallops (Fig. 7). Polyp inhabitation reduced triglyceride concentration by, on average, $23.6 \%$ in the top cage, by $47.4 \%$ in the middle cage, and by $36.4 \%$ in the bottom cage. The association rates of polyp with juvenile scallops were $0.40,0.55$ and 0.40 $(n=20)$ in top, middle and bottom cages, respectively. The locations of the polyp occurrence were mantles $(96.3 \%)$, labial palps $(63.0 \%)$, lips $(29.6 \%)$, and foot $(4.2 \%)$. The polyp did not occur on the gills of the scallops.

\section{Discussion}

Distribution of polyp of Eutima japonica in Funka Bay

Association rates with age one adult scallops were very low in November 2003, even at the sites where polyps were very common on juvenile scallops (Fig. 3a, d). Two explanations are proposed for the different colonization rates: (i) different culturing methods caused the different colonization rates; (ii) susceptibilities to settlement by hydroid planulae were different between adult and juvenile scallops. Juvenile scallops were cultured in cages, on the other hand adult scallops were cultured on hanging ropes; the quasi-closed environment inside cages might enhance intraspecific infestation in juvenile scallops by keeping medusa and planula larvae within cages. Juvenile scallops may be much more susceptible to hydroid infestation than age one adult scallops; scallops between ages zero and one may develop resistance to settlement by hydroid planulae.

Since polyps were rare in adult scallops, we believe that infection of juvenile scallops was probably initiated from the planulae produced by medusae released from polyps growing on Mytilus spp., especially M. galloprovincialis. Subsequently, the inhabitation spread intraspecifically and interspecifically.

Association rates of mussels with polyp of Eutima japonica were high in large area of Funka Bay (Fig. 3e). Because Kubota (1983) found a constant association rate of polyp with $M$. galloprovincialis throughout the year in Oshoro Bay, Hokkaido, we believe that there is likely a constant high association rate of polyp with mussels around large portions of the coast of Funka Bay. In contrast, there are large yearto-year fluctuations in the polyp occurrence in juvenile scallops in Funka Bay. We found that hydroids presence in juvenile scallops declined drastically in 2004 and 2005 (Fig. 3a-c). Hence, we believe that in most 

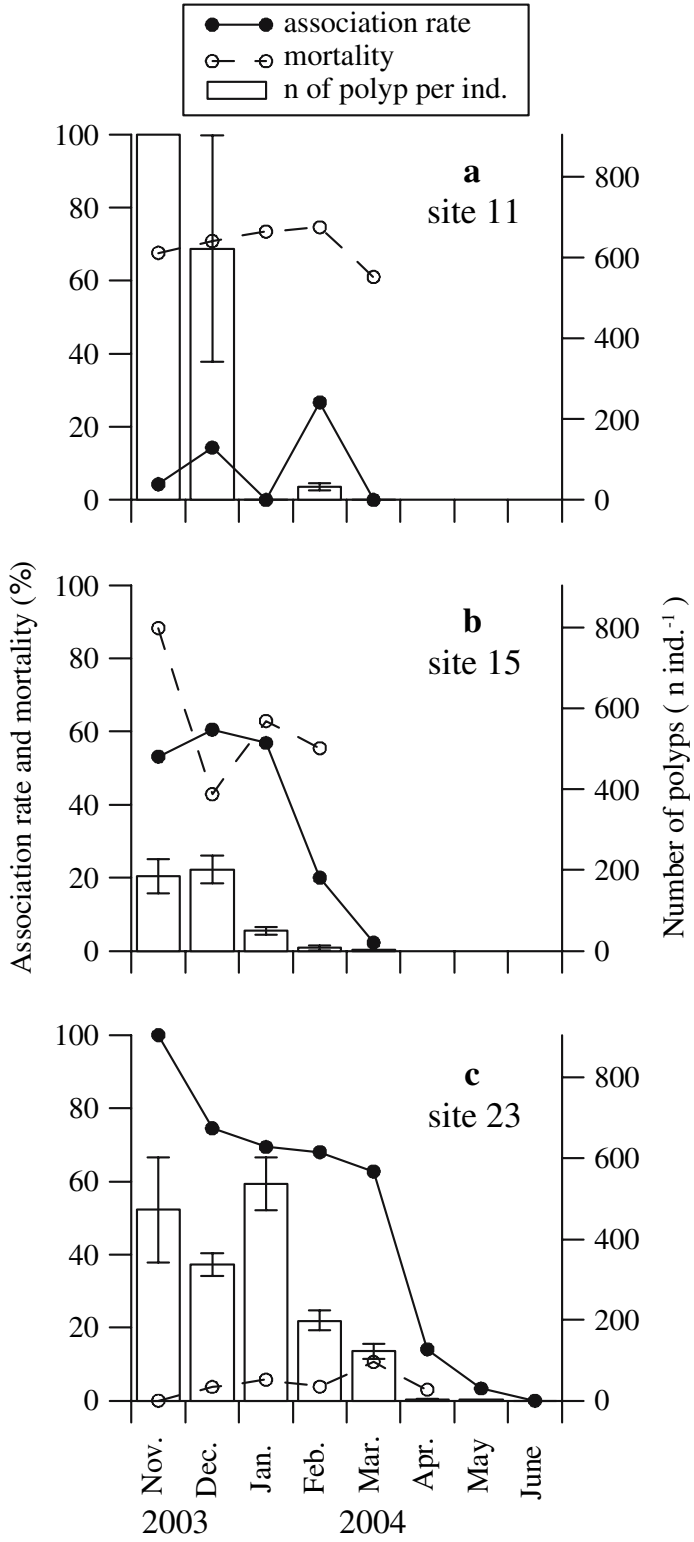

Fig. 4 Eutima japonica and Mizuhopecten yessoensis, monthly changes in association rate of $E$. japonica polyps with juvenile $M$. yessoensis; mortality of juvenile $M$. yessoensis; numbers of $E$. japonica polyps per juvenile $M$. yessoensis individual. Error bars indicate SEM, ind. individual

years, E. japonica in wild populations of mussels may have a limited ability for spreading to scallops in culture facilities located offshore. The massive polyp population in wild mussels in 2003 might have spread to the culture facilities. We could not elucidate factors for polyp outbreak in 2003.

\section{Seasonality of inhabitation in juvenile scallops}

The decrease and disappearance of infestation from juvenile scallop during the colder seasons may result from decreased asexual reproduction of polyps in
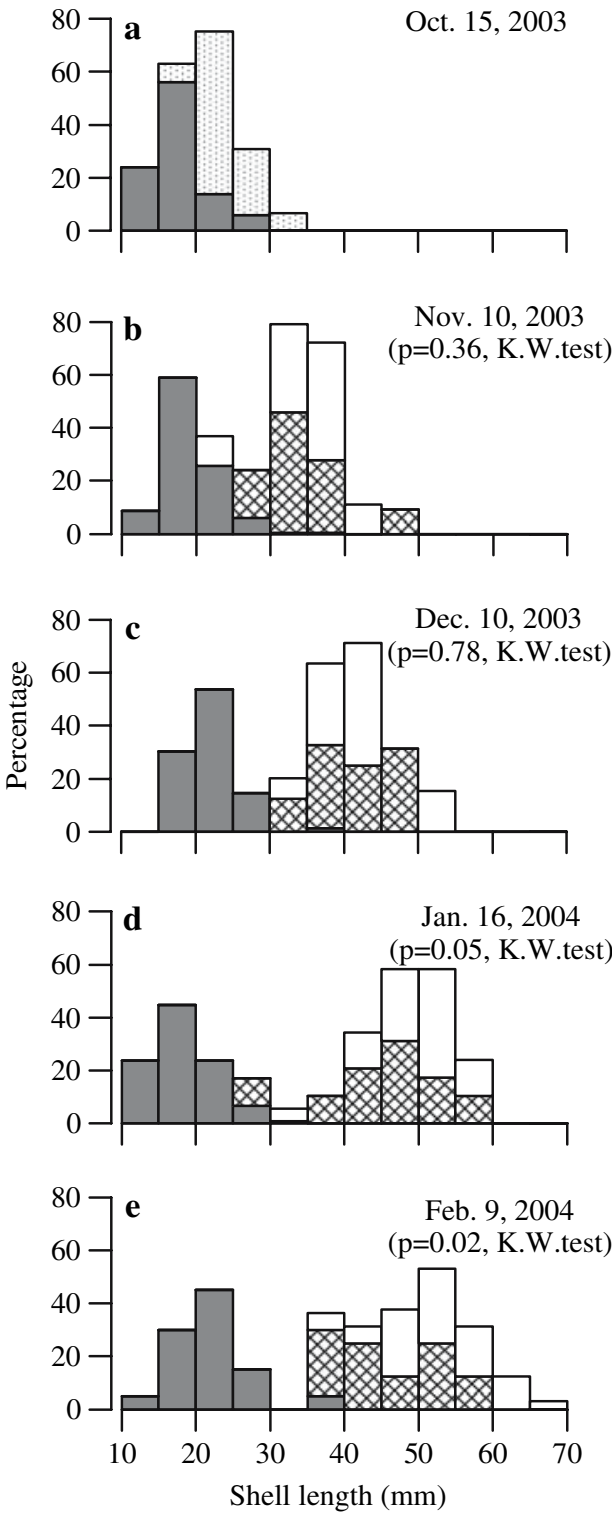

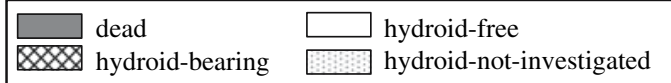

Fig. 5 Mizuhopecten yessoensis, monthly changes in shell length compositions of age zero juveniles at site 15 . For visualization, sum of percentages in each group was adjusted to $100 \%$. Samples b-e are those in Fig. 4b. Inhabitation by Eutima japonica was not investigated in October 2003. Mortality in October sample was $81.0 \%$. Results of Kruskal-Wallis test between shell lengths of hydroid-bearing and hydroid-free living juvenile scallops were shown in parentheses

winter, because polyps disappeared first from the site with the lowest association rate in November (Fig. 4a-c). Although production of daughter polyps decreases in winter as water temperatures fall, association rate of hydroid in mussels does not change thought the year (Kubota 1983). Therefore, juvenile scallops may have stronger ability to exclude polyps than mussels. 

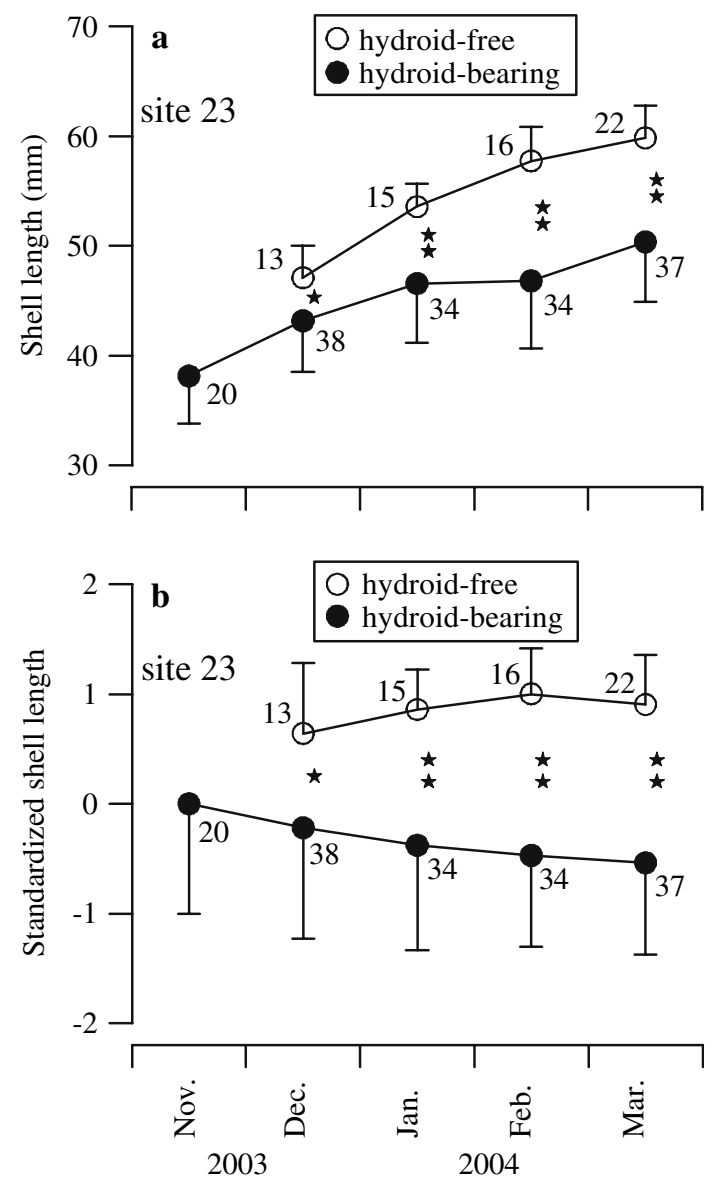

Fig. 6 Mizuhopecten yessoensis, monthly changes in shell length a and standardized shell length $\mathbf{b}$ in age zero juveniles bearing and free of the hydroid Eutima japonica at site 23. Vertical bars $=$ SDs. Stars indicate significance levels in Kruskal-Wallis tests $\left({ }^{*} P<0.01\right.$, $* * P<0.001)$. The association rate in November was $100 \%$. Samples are those in Fig. 4c. The sample sizes are shown near each plot

In the early phase of symbiosis, shell length differences between hydroid-bearing and hydroid-free juvenile scallops were not significant at site 15 (Fig. 5) and they were small at site 23 (Fig. 6a, b). There is probably no size specificity for settlement of hydroid planula on age zero juvenile scallop.

Effects of Eutima japonica inhabitation on juvenile scallops

Presence of polyps on juvenile scallops reduced shell length growth by $43.3 \%$ (Fig. $6 \mathrm{a}$, b), and triglyceride accumulation in the digestive gland by $23.6-47.4 \%$ (Fig. 7). Such detrimental effects are probably due to the stress of inhabitation and the impediment to the feeding mechanisms. The inhabitation of Eutima japonica on juvenile scallop is best regarded as parasitism, rather than inquilinism or commensalism. Inquilinism and commensalism are defined as symbioses in which symbionts

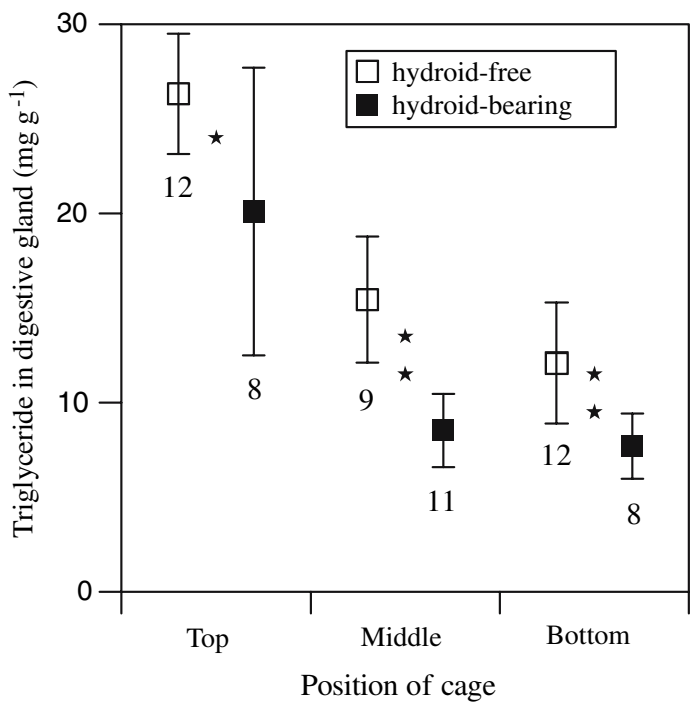

Fig. 7 Mizuhopecten yessoensis, triglyceride concentrations in digestive glands of age zero juvenile bearing and free of the hydroid Eutima japonica (sampled at site 20 on 15 November 2004). Vertical bars $=$ SDs. Stars indicate significance levels in KruskalWallis tests $(* P<0.01 ; * * P<0.001)$. The sample sizes are shown under each plot

do not adversely affect their hosts, and parasitism is defined as a symbiosis in which a symbiont, to a greater or lesser extent, has detrimental effects on the host (Lincoln et al. 1998). It appears that M. galloprovincialis is not negatively affected by Eutima japonica and Eugymnanthea inquilina (Kubota 1983; Piraino et al. 1994). Piraino et al. (1994) suggested that the relationship between M. galloprovincialis and Eugymnanthea inquilina is a mutualism, rather than simple inquilinism, because E. inquilina selectively ingests trematode sporocysts that are parasites for $M$. galloprovincialis. During evolution of mutualism, reduction of detrimental effects of the parasite on the host is accompanied by development of host dependency (by the parasite) en route mutualism (Boucher 1982). The detrimental effects of Eugymnanthea inquilina on $M$. galloprovincialis might have been reduced during their coevolution. Hence, the impact of the hydroid inhabitation on juvenile scallops is different from that on mussels.

Mizuhopecten yessoensis and Mytilus galloprovincialis have anatomically different feeding structures. The scallop has well developed (hypertrophied) lips, which interdigitate over the mouth (Beninger and Pennec 1991; Slack-Smith 1998). The mussel does not have lips. In the European scallop, Pecten maximus, the numerous pores between lips allow water to flow through, and the thick ciliated epithelium on their internal ridges prevents the loss of food particles (Gilmour 1974). It is possible that these anatomical differences account in part for differences in the effects 
of polyp inhabitation in scallops and mussels. However, only a small percentage of juvenile scallops (29.6\%) had polyps attached to lips. The inhabitation likely imposes some degree of stress on juvenile scallops.

Relationship between hydroid inhabitation and massive death

In each October from 1996 through 2006, the Hokkaido Oshima Hokubu District Fisheries Training Center (unpublished data; 228-1 Morikawa, Mori, Hokkaido 049-2313, Japan) has investigated mortalities and shell lengths of juvenile scallops sampled from 17 to 33 producers (varies by year), who culture scallops in sites 13 through 34 (Fig. 1). Highest mortalities occurred in $2003($ mean $=22.0 \%, \mathrm{SD}=24.2, n=24)$, followed by $2004($ mean $=10.6 \%, \quad \mathrm{SD}=9.6, n=33)$, and 1999 (mean $=9.7 \%, \mathrm{SD}=9.5, n=27)$. In other years, mortalities were less than $4 \% \quad$ (mean $=2.6, \quad S D$ of mean $=1.03, n=17-31)$. Thus, the massive die off in 2003 was extraordinary.

Inhabitation of hydroid may not be a direct lethal factor for juvenile scallops because there were sites where association rates were high, but mortalities were low (site 19-27; Fig. 3a, f). However juveniles may have been stressed by the inhabitation. Massive death occurred within 1 month after aquaculture producers transferred juveniles from pre-intermediate culture cages to intermediate culture cages. We believe that the massive death may result from transferring juveniles that were already heavily inhabited by hydroids, because, other than hydroids, juvenile-specific parasites have not been reported in scallops, and massive death in 2003 occurred only in juvenile scallops. Adults were uninfected. Actually, we did not see any parasites other than hydroid, e.g., ciliates, in juvenile scallops during our observations. When juvenile are transferred by the producers, a check (false ring) is formed in the shells, which is indicative of stress.

In November 2003, there were four categories of relationship between the polyp/scallop association rates and mortalities of juvenile scallops: I, low association rate and high mortality (sites 9-11); II, high association rate and high mortality (sites 13-18); III, high association rate and low mortality (sites 19-27); IV, low association rate and low mortality (sites $2-8$ and 28-35) (Fig. 3a, f). We believe that in 2003, the hydroid inhabitation began in area I and spread to area II and then area III. When producers carried out transfer juveniles from pre-intermediate culture cages to intermediate culture cage (mainly in mid or late September), most of juveniles in area I may have been heavily inhabited by hydroid polyps to levels that made them unable to tol- erate transfer stress. Subsequently, most died in area I. Hence, at site 11 in area I, association rates were low, and large numbers of polyps and high mortalities were observed (Fig. 4a). During the transfer process, some of juveniles in area II may have been carrying a polyp load that made the stress unbearable, while others were carrying a lighter load. Hence, at site 15 in area II, association rates were intermediate, and relatively small numbers of polyps and high mortalities were observed (Fig. 4b). During the transfer process, the polyp load in area III may have been at a tolerable level for surviving the handling stress. Thus, we observed high association rates, large numbers of polyps and low mortalities at site 23 (Fig. 4c). Since different producers carry out aquaculture operations at each site, these differences between the polyp/scallop association rates and mortalities of juvenile scallops were not caused by different handling procedures among aquaculture producers. If handling procedure differences among producers were causing differences in symbiotic association rates and mortalities of juvenile scallops, the effect would be randomly distributed among areas and not localized.

In Japan, Eutima japonica is distributed from Sagami Bay $\left(35.3^{\circ} \mathrm{N}, 139.2^{\circ} \mathrm{E}\right)$ to Funka Bay $\left(42.3^{\circ} \mathrm{N}\right.$, $\left.140.3^{\circ} \mathrm{E}\right)$ on the pacific coast, and in the Sea of Japan off the southern shore of Hokkaido (Kubota 1992a). There is a possibility that juvenile scallops cultured in these areas suffer some stress from hydroid inhabitation. When other stresses occur concurrently, there is a risk of massive mortalities.

In Funka Bay, scallops are produced commercially as a food source and as a seed stock for scallop cultures in other areas. Eugymnanthea spp. and Eutima spp., occur in many bivalve species (Kubota 1992a, 1997), including those used for human food, but no harmful effects on humans have been reported. Eutima japonica rarely infects age one scallops at market size. Scallop seed is usually exported in June or later, after E. japonica has disappeared from the juvenile scallops. Hence, $E$. japonica does not degrade the quality of product in Funka Bay for either food use or for seed stock.

Acknowledgment We would like to thank staffs of the Oshima Hokubu District Fisheries Training Center and the Iburi District Fisheries Training Center for their warm cooperation in field sampling, and Mr. Y. Kuwahara for his assistances for classification of Mytilus spp.

\section{References}

Barber BJ, Blake NJ (1991) Reproductive physiology. In: Shumway SE (ed) Scallops: biology, ecology and aquaculture. Elsevier, Amsterdam, pp 377-428 
Beninger PG, Pennec ML (1991) Functional anatomy of scallops. In: Shumway SE (ed) Scallops: biology, ecology and aquaculture. Elsevier, Amsterdam, pp 133-223

Boucher DH, James S, Keeler KH (1982) The ecology of mutualism. Annu Rev Ecol Syst 13:315-347

Gilmour THJ (1974) The structure, ciliation, and function of the lips of some bivalve molluscs. Can J Zool 525:335-343

Ito H (1991) Fisheries and aquaculture, Japan. In: Shumway SE (ed) Scallops: biology, ecology and aquaculture. Elsevier, Amsterdam, pp 1017-1055

Kubota S (1979) Occurrence of a commensal hydroid Eugymnanthea inquilina Palombi from Japan. J Fac Sci Hokkaido Univ Ser VI Zool 21:396-406

Kubota S (1983) Studies on life history and systematics of the Japanese commensal hydroids living in bivalves, with some reference to their evolution. J Fac Sci Hokkaido Univ Ser VI Zool 23:296-402

Kubota S (1991) The stability of diagnostic characters of the medusa of a bivalve-inhabiting hydrozoan Eugymnanthea japonica Kubota in Japan. Proc Jpn Soc Syst Zool 44:1-7

Kubota S (1992a) Four bivalve-inhabiting hydrozoans in Japan differing in range and host preference. Sci Mar 56:149-159

Kubota S (1992b) Eucheilota intermedia Kubota is a district taxon and the third form of Eutima japonica Uchida (Hydrozoa, Leptomedusae). Zool Sci 9:231-235
Kubota S (1997) A new form of the bivalve-inhabiting hydrozoan Eutima japonica (Leptomedusae, Eirenidae) in Japan. Public Seto Mar Biol Lab 38:73-81

Kuwahara Y (2001) Mytilus trossulus and Mytilus galloprovincialis in Hokkaido. In: The sessile organisms society of Japan (ed) Kuroshouzoku no shinnyuusha. Koseisha Koseikaku, pp 7-26 (in Japanese)

Lincoln R, Boxshall G, Clark P (1998) A dictionary of ecology, evolution and systematics, 2nd edn. Cambridge university press, Cambridge

Ministry of Agriculture, Forestry and Fisheries (2000-2005) Statistics on agriculture, forestry and fisheries. Tokyo, Japan

Okutani T, Kubodera T, Kurozumi T, Saito H, Sasaki T, Tsuchida E, Tsuchiya K, Hasegawa K, Hamatani I, Hayami I, Hori S, Matsukuma A (2000) Marine mollusks in Japan. Tokai University Press, Tokyo

Piraino S, Todaro C, Geraci S, Boero F (1994) Ecology of the bivalve-inhabiting hydroid Eugymnanthea inquilina in the coastal sounds of Taranto (Ionina Sea, SE Italy). Mar Biol 118:695-703

Slack-Smith SM (1998) Order ostreoida. In: Beesley PL, Ross GJB, Wells A (eds) Mollusca: the Southern synthesis. Fauna of Australia. CISRO Publishing, Melbourne, Part A 5:268282 